Jasna Prpić-Oršić

Odd Magnus Faltinsen

Joško Parunov

http://dx.doi.org/10.21278/brod67303

ISSN 0007-215X

eISSN 1845-5859

\title{
INFLUENCE OF OPERABILITY CRITERIA LIMITING VALUES ON SHIP SPEED
}

UDC 629.5.016/.017

Original scientific paper

\begin{abstract}
Summary
When the ship is caught in heavy seas, there are two manoeuvres that the shipmaster can undertake to avoid excessive ship motion and hull damage: changing course or voluntary speed reduction. This paper presents a study of the effect of the various voluntary speed reduction criteria to attainable speed of ship on seaway. The speed loss is calculated by taking into account wind and wave effect on ship speed, the engine and propeller performance in actual seas as well as the mass inertia of the ship. The attainable ship speed for ship in head, following and beam waves by accounting for voluntary speed reduction is estimated for various significant wave height. The criteria of slamming, deck wetness, propeller emergence, excessive accelerations and roll are taken into account. The impact of variations of the limiting values of certain criteria due to which the captain intentionally reduces the ship speed is analysed and discussed.
\end{abstract}

Key words: Operability criteria; Seakeeping; Voluntary speed reduction

\section{Introduction}

The ship behaviour in actual weather condition is currently one of the major concerns for designers and ship owners as well as for ship officers. Each one of them has their own preoccupations. From the designer's point of view, the competition between design offices has stimulated the effort of more accurate ship performance evaluation. Ship officers want a fast and safe ship with good performance in actual seas. On the other hand, ship owners are oriented towards achieving the highest possible profit in given conditions and restrictions. In this respect, the accurate calculation of attainable ship speed at higher sea states is essential from economical and also environmental aspects. A reliable speed loss calculation allows a more accurate prediction of the power increase and fuel consumption as well as gas emissions from ships. 
When the ship is caught in heavy seas, there are two manoeuvres that the shipmaster can undertake to avoid excessive ship rolling and hull damage [1]. These are:

changing course,

voluntary speed reduction.

The course changes in heavy weather are mainly to avoid the ship capsizing or excessive ship rolling amplitudes that may interfere with normal working activities on board [1]. Consequently, the probability of head seas is much higher in heavy weather than in normal sea conditions. However, this is valid only for smaller ships (less than about $200 \mathrm{~m}$ in length). For larger ships, the course changes in heavy weather are not so frequent [2]. The explanation for this finding could be that the masters of large ships feel safe even in rather rough seas.

Another important manoeuvre in rough seas is the speed reduction. This action is not dependent on the ship size [1]. The reasons for speed reduction may generally be divided into two categories:

- natural reasons, such as the added resistance due to wind, waves and current, steering, change of wake field and loss of thrust [3].

- technical or "design" reasons that are controlled by the shipmaster, such as very large motion amplitudes, velocities and accelerations, slamming, green seas, overload of the main engine.

The natural reasons influence the ship speed at relatively low significant wave heights $\mathrm{H}_{\mathrm{s}}$, while in heavy seas the shipmaster decides whether to reduce speed. There is no strict rule that determines under which conditions the shipmaster would reduce the speed, so various authors have proposed different criteria [4].

One of the general indicator of ship quality is the ability to maintain speed in severe head seas. The excessive motions, slamming, deck wetness, propeller emergence, excessive accelerations are the main causes of the master's decision to reduce ship speed and avoid ship or cargo damage or people injuries. This decision is very subjective and greatly depends on the master's expertise and experience but for the ship design purpose it is possible to take into account some average behaviour [2]. This average behaviour must be expressed by numerical values in order to be applicable for numerical analysis. In this paper the research on the sensitivity of final results, in our case - ship speed, on those values variation, presented by Prpić-Oršić et al., [5], is extended on beam sea where rolling criteria are relevant.

\section{Methodology of attainable speed estimation}

The speed that ship can attain in calm sea depends on still water resistance, engine and propeller characteristics. A ship slows down either involuntarily due to increased resistance from the wind and waves, or voluntarily due to navigation hazards or fear of heavy weather damage from excessive ship motions and accelerations, propeller racing, slamming or boarding seas ([6], [7], [8], [9]).

In rough weather the resistance changes due to wave, wind loads, and due to propeller efficiency change because of different working environment compared to calm weather case. In most of the cases, the ship speed changes involuntary because of weather conditions change. This speed loss could be only few knots, but it will result with higher fuel consumption and financial losses as well as higher greenhouse gases emissions.

Prpić-Oršić \& Faltinsen [9] developed a methodology of attainable speed estimation in various operating conditions, Fig. 1 . The calculation of added resistance in regular waves is carried out by a direct pressure integration method in the wavelength range of non-negligible ship motions together with a small-wavelength asymptotic formula developed by Faltinsen et 
al. [10]. The irregular sea is approximated by a decomposition of irregular wave time trace into a series of regular wave parts. The added resistance in regular waves are used in performing calculations in the regular wave parts. Accounting for the effect of still water resistance and added resistance as well as for air resistance and thrust loss in waves, the attainable ship speed for a constant engine torque is obtained by accounting for the mass inertia of the ship and engine performance.

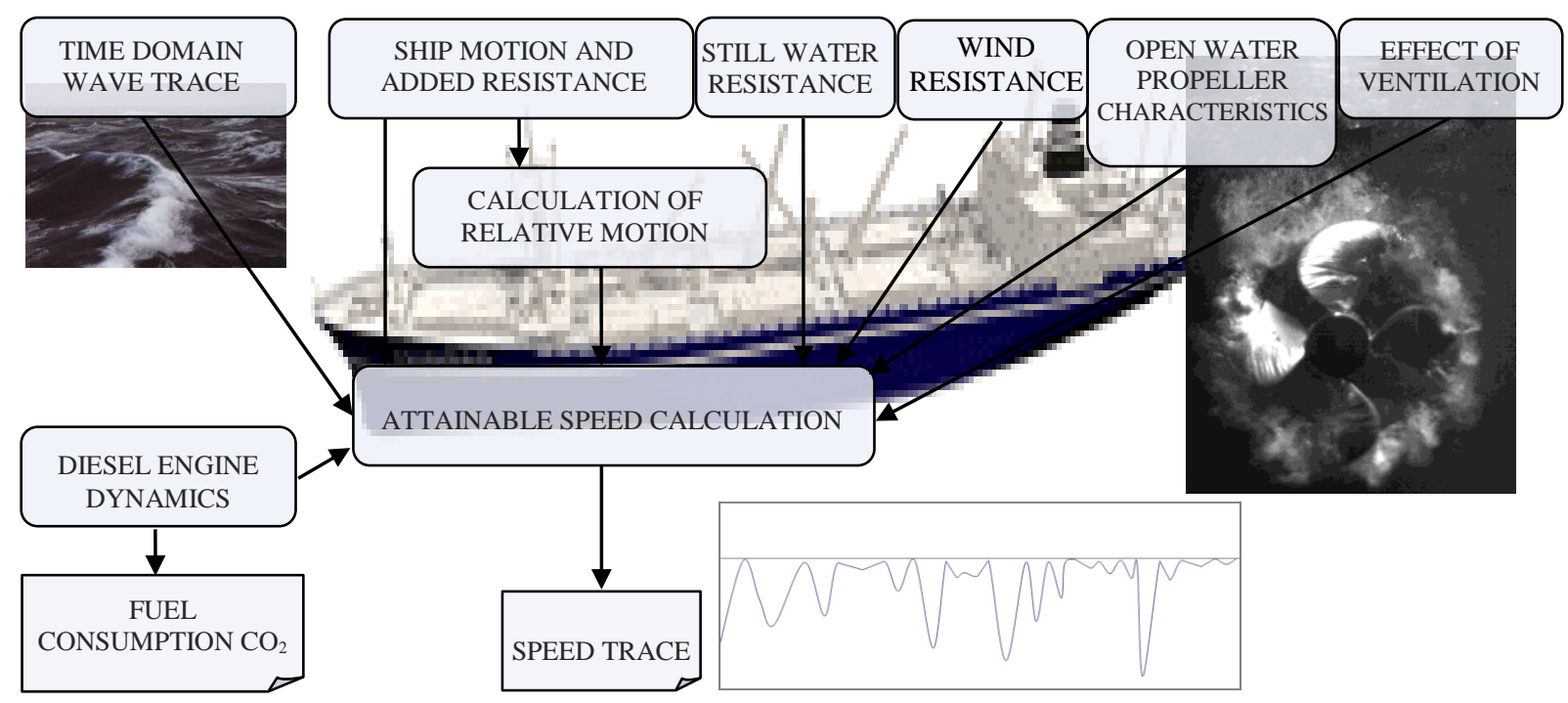

Figure 1. Scheme of the computations of ship speed in a given sea state

The wind loads on ships constitute a relatively small, yet important part of the environmental loads. The wind force depends on wind speed, ship area above waterline and drag coefficients. The drag coefficients are calculated by the Blendermann model ([11], [12], [13]) and exposed area is taken as $450 \mathrm{~m}^{2}$.

The total wind velocity is a combination of a steady-state or mean velocity and a turbulent (gust) velocity. The mean speed is calculated as a function of significant wave height according to the one-parameter Pierson-Moskowitz spectrum. The gust component is a random process with zero mean and a spectrum called the gust spectrum which could be calculated according to Harris [14]. The wind direction is assumed to be the same as wave direction.

At higher sea states, the ship is subjected to very strong environmental forces and consequently experiences several additional dynamic effects, which affects her speed. The relative vertical motion could be very pronounced and the consequence is that the propeller operates too close to the surface of the water or even periodically operates out of the water. In these cases, the propeller will obviously behave differently than in calm water or small seas. Since this phenomenon is very difficult to solve numerically, we tried to capture the effect by implementing a thrust loss model using available experimental data by Smogeli [15]. As a result, the time trace of ship speed could be obtained for any specific sea state. According to calculated mean speed at specific sea state the increase of fuel consumption as well as $\mathrm{CO}_{2}$ emission at sea could be also estimated. The numerical model used for main propulsion engine modelling is based on a zero-dimensional model of an internal combustion engine. A number of control volumes interconnected with links for mass and energy transfer between them [16], represents the main propulsion engine. 


\section{Voluntary speed reduction}

When the ship encounters the storm or heavy sea, the master will probably reduce voluntarily the ship speed in order to avoid severe consequences. He or she decides to slow down in situations when excessive motions jeopardize the ship, crew or cargo. In most of the cases these situations are related to slamming, deck wetness, excessive vertical accelerations on bow and propeller emergence. The decision that one master will take under specific circumstances is very subjective and can greatly depend on experience and ability to properly estimate the potential danger. Consequently, it is very hard to predict the master's decisions during heavy weather but we can assume some average behaviour. However, at this point, the calculation is source of lot of uncertainties and the result depends on the limiting values we used as criteria when the master will reduce the speed. Several authors dealt with this kind of problem and a short overview can be found in Faltinsen \& Svensen [17] and Journee [18].

Once when the criteria and the limiting values are chosen the question of how the master will slow down is posed. Some masters tend to immediately slow down significantly and to reach very low speed as soon as possible (about $10 \mathrm{kn}$ for example). Others will slow down moderately step by step and monitor how the ship behaves. Once again, this is a very subjective decision and it could be only taken into account as some average behaviour.

Ship operability criteria which are used for safety assessment and thus for the deliberate reduction of ship speed, can be generally divided into several groups: criteria related to the movement of the ship, criteria related to the acceleration and criteria linked to a specific phenomenon such as the emergence of the propeller, deck wetness or bow (stern) slamming. However, limiting values of each criterion can vary for different ship types and relative speed. Moreover, different classification societies and authorities recommend different values.

The selection of the relevant criteria will depend on tasks that the ship must complete. Therefore, it is essential to identify the tasks and responses that jeopardize the task performance. Having determined the relevant criteria, which are believed to influence performance, the next step is to estimate the restrictive values of each criterion. The only practical method to determine criteria and limiting values is to observe ship (crew) apparent performance in real operational conditions. This could be done by using questionnaires in order to have a feedback from shipmasters. Questions must be carefully made in order to allow the shipmaster to precisely define the conditions, which are believed to threaten the ship (crew). They must be set in a way that allows the numerical expression of limiting values. Another way to identify the criteria limits is to monitor the ship performance through various parameters (motion, speed, engine power, weather condition, recording in logbook) over a long period (months or year). From such data correlation and analysis, it is possible to draw conclusions about phenomena that precede the ship speed reduction or interruption of other operations.

\section{Influence of operability criteria limiting values}

The calculations have been performed for the S-175 containership. The main particulars of the ship are given in Table 1. [19]. For main engine dynamic simulation the scaled model of two-stroke low speed marine engine, with main particular listed in Table 2. is used. A fixed pitch propeller of 5.6-meter diameter with six blades is used in the numerical example.

The wave realization is obtained from the one-parameter ITTC spectrum. The mean speed loss, obtained as average value during time simulation, represents the reduction from $21.9 \mathrm{kn}$ speed and includes voluntary speed loss in severe seas. In this particular calculation, the criteria used for voluntary speed reduction are slamming, deck wetness, bow vertical acceleration, propeller emergence and roll angle. 
Table 1. Main particulars of the S-175 container ship

\begin{tabular}{l|l} 
Length between perpendiculars & $175.0 \mathrm{~m}$ \\
\hline Breadth moulded & $25.4 \mathrm{~m}$ \\
\hline Design draft & $9.5 \mathrm{~m}$ \\
\hline Freeboard & $7.0 \mathrm{~m}$ \\
\hline Displacement & 24272 tonnes
\end{tabular}

\begin{tabular}{l|c} 
Table 2. Characteristics of the main engine \\
Main Engine \\
6S50MC-C
\end{tabular}

The time trace of attainable speed estimation for ship in head, following and beam waves by accounting for voluntary speed reduction are shown $\left(H_{s}=5 \mathrm{~m}\right.$ and $\left.7 \mathrm{~m}\right)$ in Fig. 2 to 4. For that case, limiting values for slamming according to Ochi criteria [20], deck wetness and propeller emergence are taken as probability $0.01,0.05$ and 0.1 , respectively. The excessive accelerations and roll criteria limits are expressed as rms (root mean square) values. For the vertical acceleration and roll the adopted limiting rms value is 0.215 times gravity acceleration and 2 degrees respectively.

The occurrences of each criteria limit exceedance in the figures are marked with different labels. It can be seen that in head waves at $H_{s}=5 \mathrm{~m}$, as well as at $H_{s}=7 \mathrm{~m}$, speed is reduced because all criteria limits are exceeded. In following waves at $H_{s}=5 \mathrm{~m}$ propeller emergences occur. At higher sea state $\left(H_{s}=7 \mathrm{~m}\right)$ ship is subjected to slamming and green water as well. In beam sea at $H_{s}=5 \mathrm{~m}$, as well as at $H_{s}=7 \mathrm{~m}$, speed is reduced because roll limit is exceeded.

In order to explore what is the sensitivity of the final result (mean ship speed) on voluntary speed reduction limiting values are systematically changed. For each criterion, the calculations are performed for three different limiting values, endeavouring that they remain into realistic values range.

Limiting values for slamming and propeller emergence are taken as probability 0.01 , 0.02 and 0.03 . The probabilities for deck wetness are taken as 0.05, 0.06 and 0.07 . For the vertical acceleration the adopted limiting rms values are $0.1,0.2$ and 0.3 times gravity acceleration. Limiting rms values for roll are taken as 2, 4 and 6 degrees. In each calculation case the limiting values for just one criterion are chosen while other criteria are not taken into account. In that way, counting also the case of involuntary speed reduction, the attainable ship speed for 13 criteria limiting value cases are calculated. Values of mean speed loss, both involuntary and voluntary, are obtained for significant wave height $H_{\mathrm{s}}$ from zero to $8 \mathrm{~m}$. 

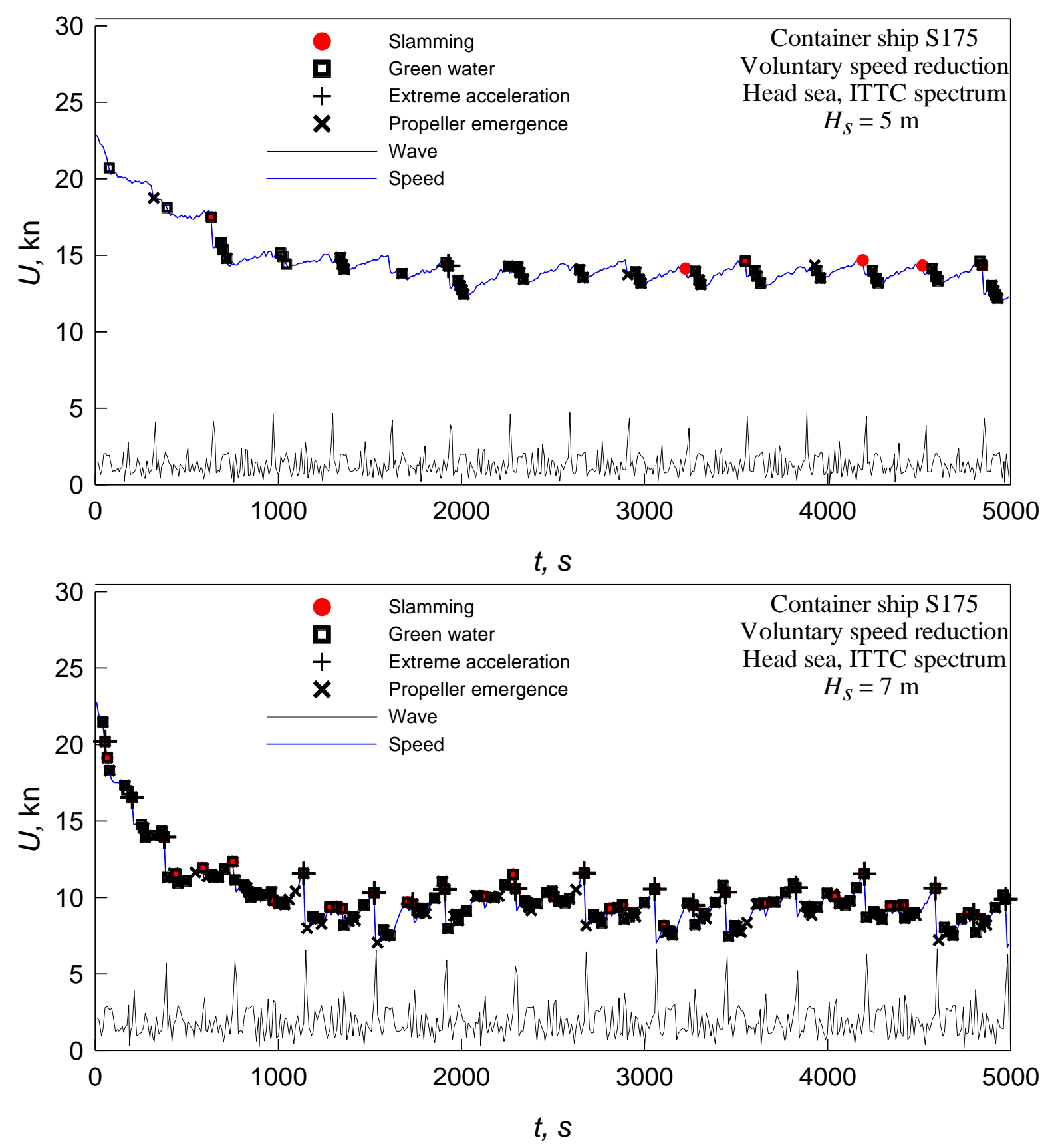

Figure 2. Time trace of ship speed in head sea 

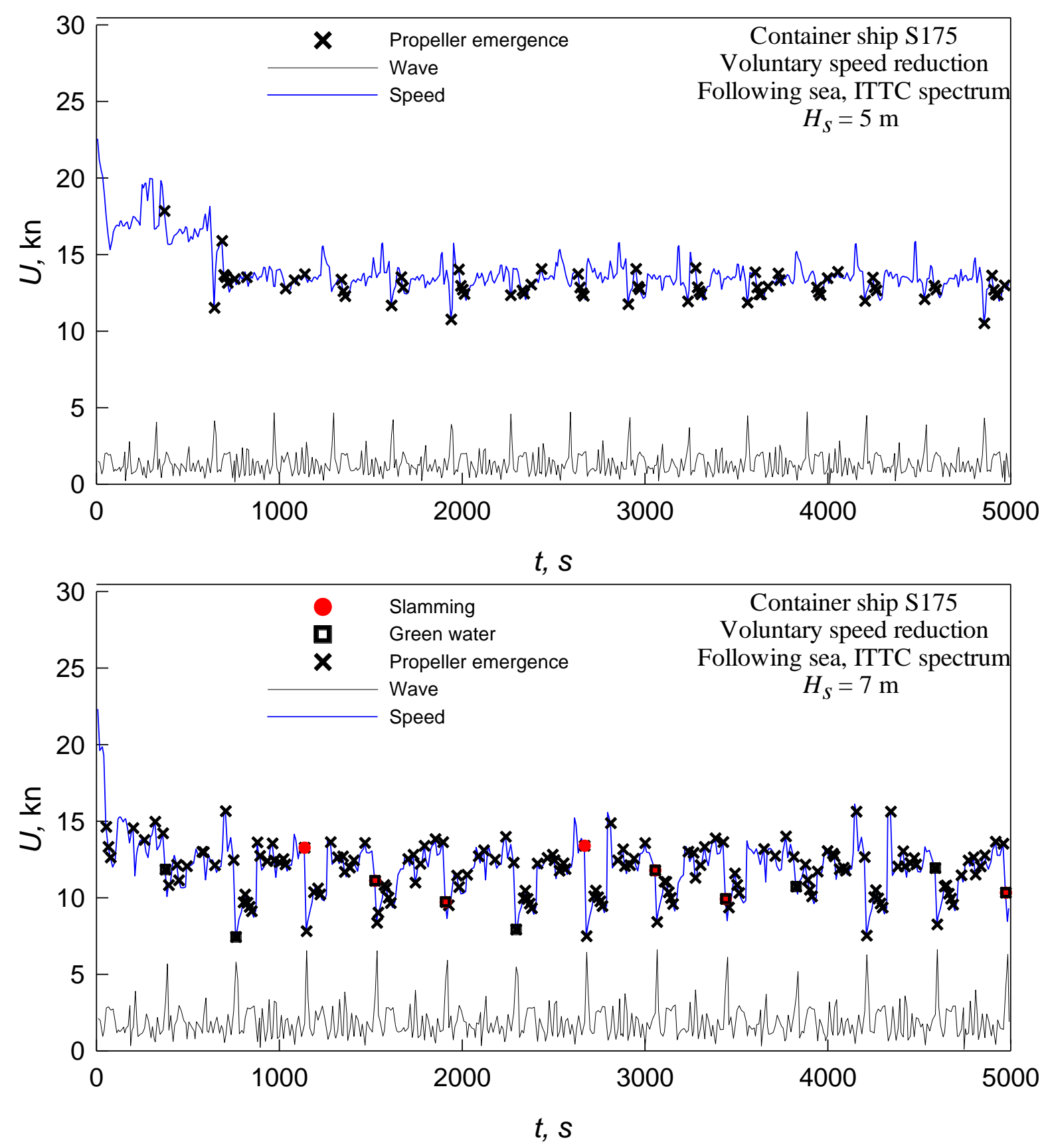

Figure 3. Time trace of ship speed in following sea 

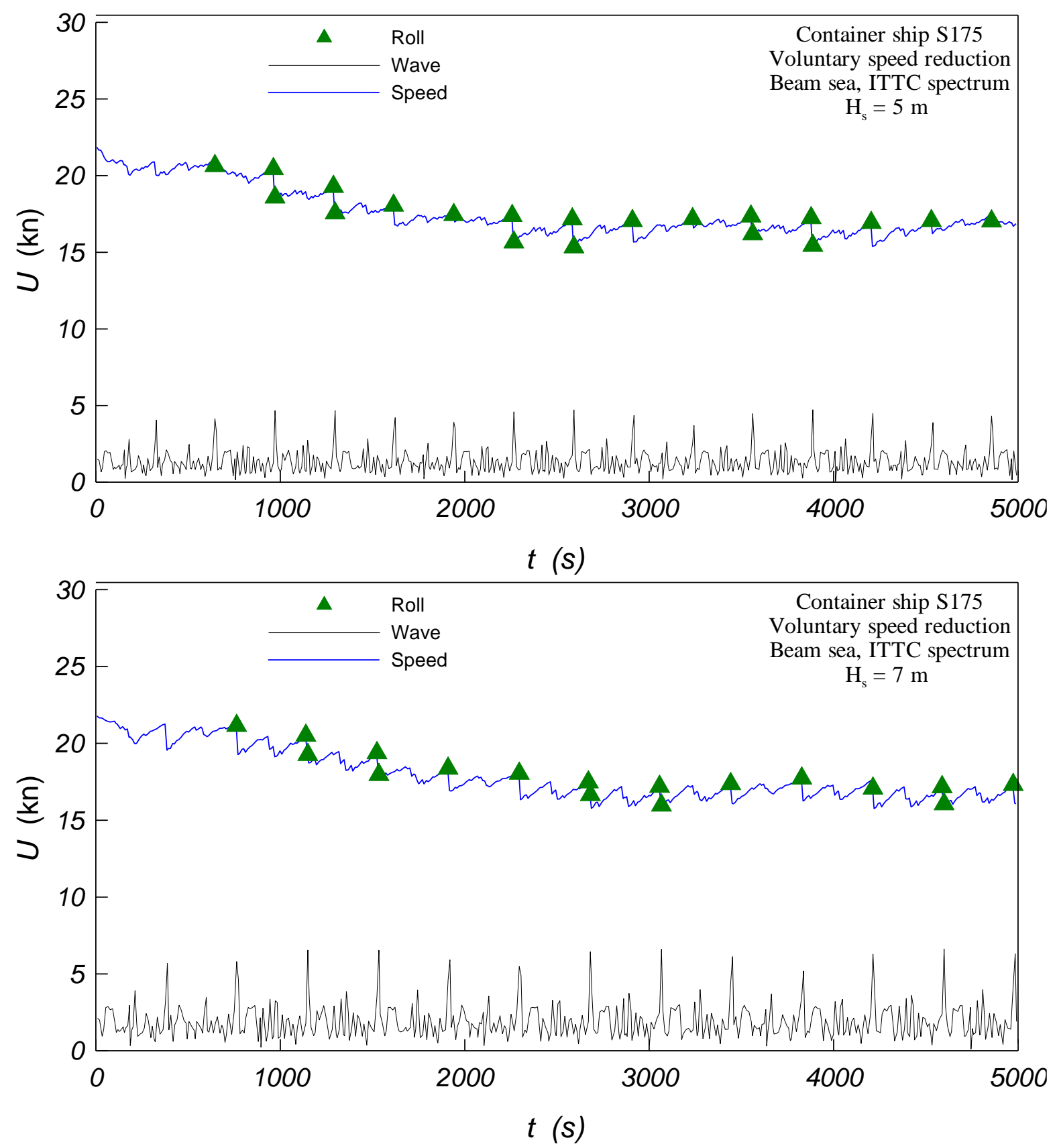

Figure 4. Time trace of ship speed in beam sea

The attainable speed is calculated for head, following and beam waves obtained for the most probable zero crossing periods related to specific sea states using ITTC spectrum. For the practical purpose, the calculated mean ship speed for a wide range of different sea states (combinations of significant wave heights and zero crossing periods) and heading angles must be used. The probability of ship operation in each sea state must be estimated according to operational area conditioned by chosen route [21]. 


\subsection{Head sea case}

The curves at Fig. 5 refer to involuntary speed reduction and to different cases of limiting values of voluntary speed reduction criteria. According to calculation, for this particular ship, the master would reduce main engine power at the weather condition of approximately $3 \mathrm{~m}$ significant wave height. This would happen due to deck wetness and propeller emergence, but mostly due to excessive accelerations (limiting rms values $0.1 \mathrm{~g}$ and $0.2 \mathrm{~g}$ ). In the range of significant wave height values of 3 to 5 meters, the attainable speed is most reduced when accounting for excessive accelerations (up to $14.4 \mathrm{kn}$ ). For the cases of significant wave height higher than $5 \mathrm{~m}$ the prevailing criterion would be deck wetness (attainable speed of $8 \mathrm{kn}$ at $H_{\mathrm{s}}=8 \mathrm{~m}$ ).

Figs. 5 to 9 show the sensitivity of final result (attainable ship speed) on criteria limit variations. Figures respectively refer to slamming, deck wetness, excessive acceleration, propeller emergence and roll criteria. The values of attainable ship speed for the specific criteria limiting values are compared with the results for involuntary speed reduction as well. The probability of slamming was varied within the range from 1 to 3 slams per 100 wave encounters. Fig. 6 shows that the speed drop is, regardless of significant height value, not very sensitive to varied limiting values. For this particular case, this is obviously due to the fact that slamming does not occur at significant wave height up to $8 \mathrm{~m}$.

For the case of deck wetness limiting value variations, (Fig. 7) the values of ship speed does not differ from the involuntary speed reduction case up to $H_{\mathrm{s}}=4 \mathrm{~m}$. At significant wave height of $5 \mathrm{~m}$ and higher the influence of accounting for deck wetness is obvious, but the effect of different limiting values on speed is negligible.

However, variations of limit acceleration values have evident impact on estimated ship speed (Fig. 8). Due to stricter limiting rms values as $0.1 \mathrm{~g}$, estimated speed varies up to 4 knots. This is not the case for the effect of propeller emergence limiting value on attainable ship speed (Fig. 9). The effect of taking this criterion into account is visible, but attainable ship speed value is not sensitive to the variation of the limiting values. As expected, rolling criteria does not have any effect (Fig. 10). 


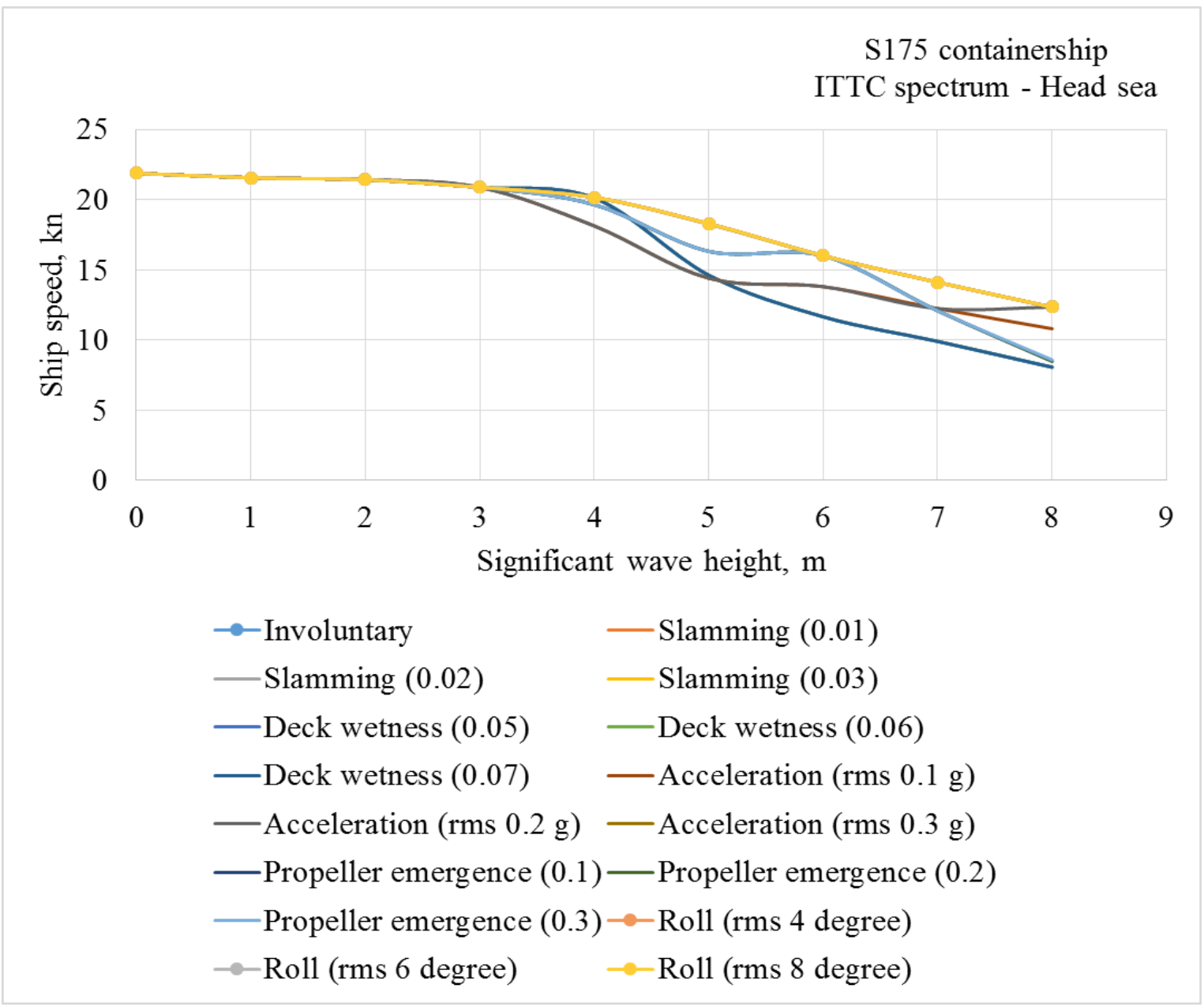

Figure 5. Ship speed loss for head sea

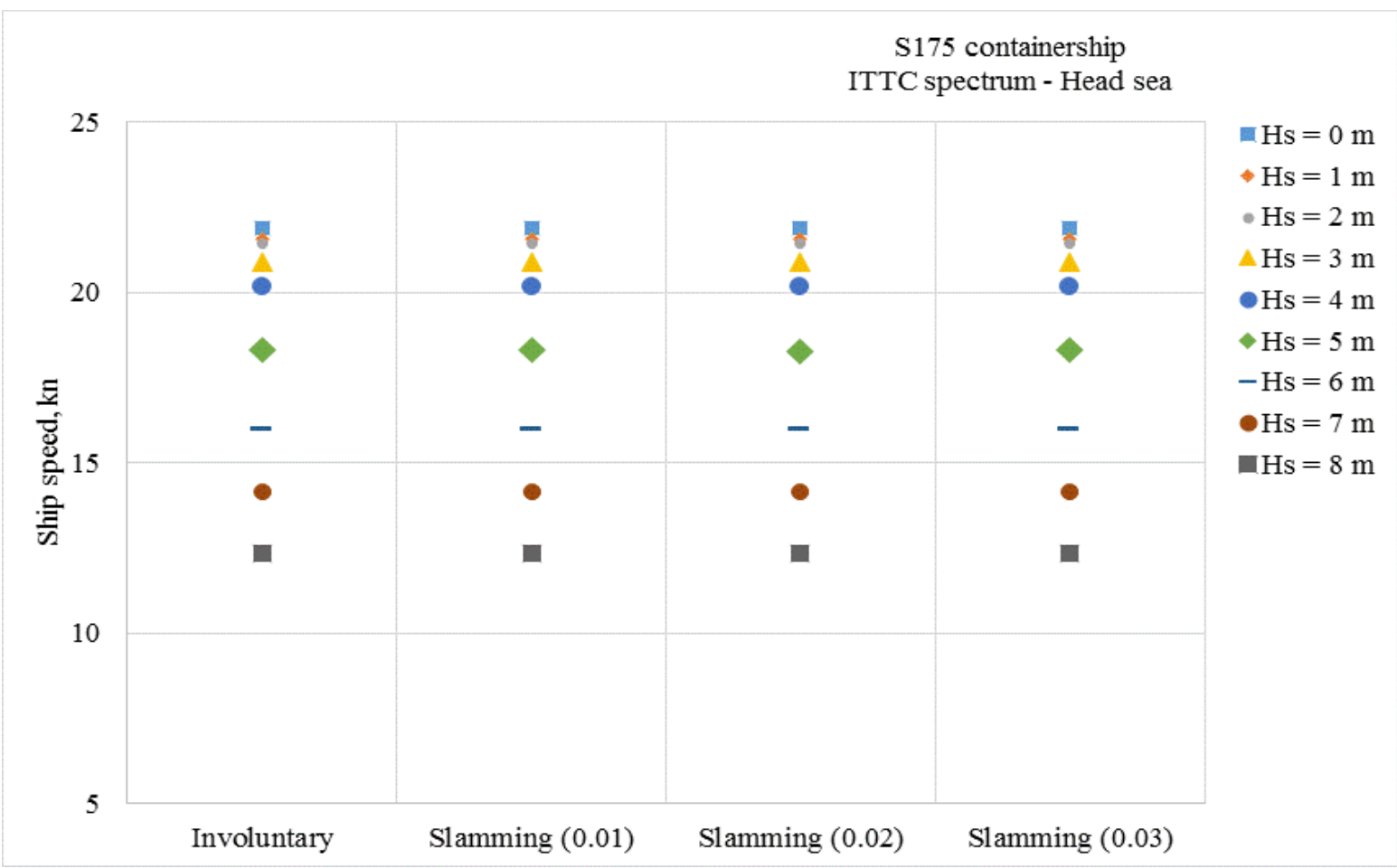

Figure 6. The effect of slamming limiting value on attainable ship speed (head sea) 


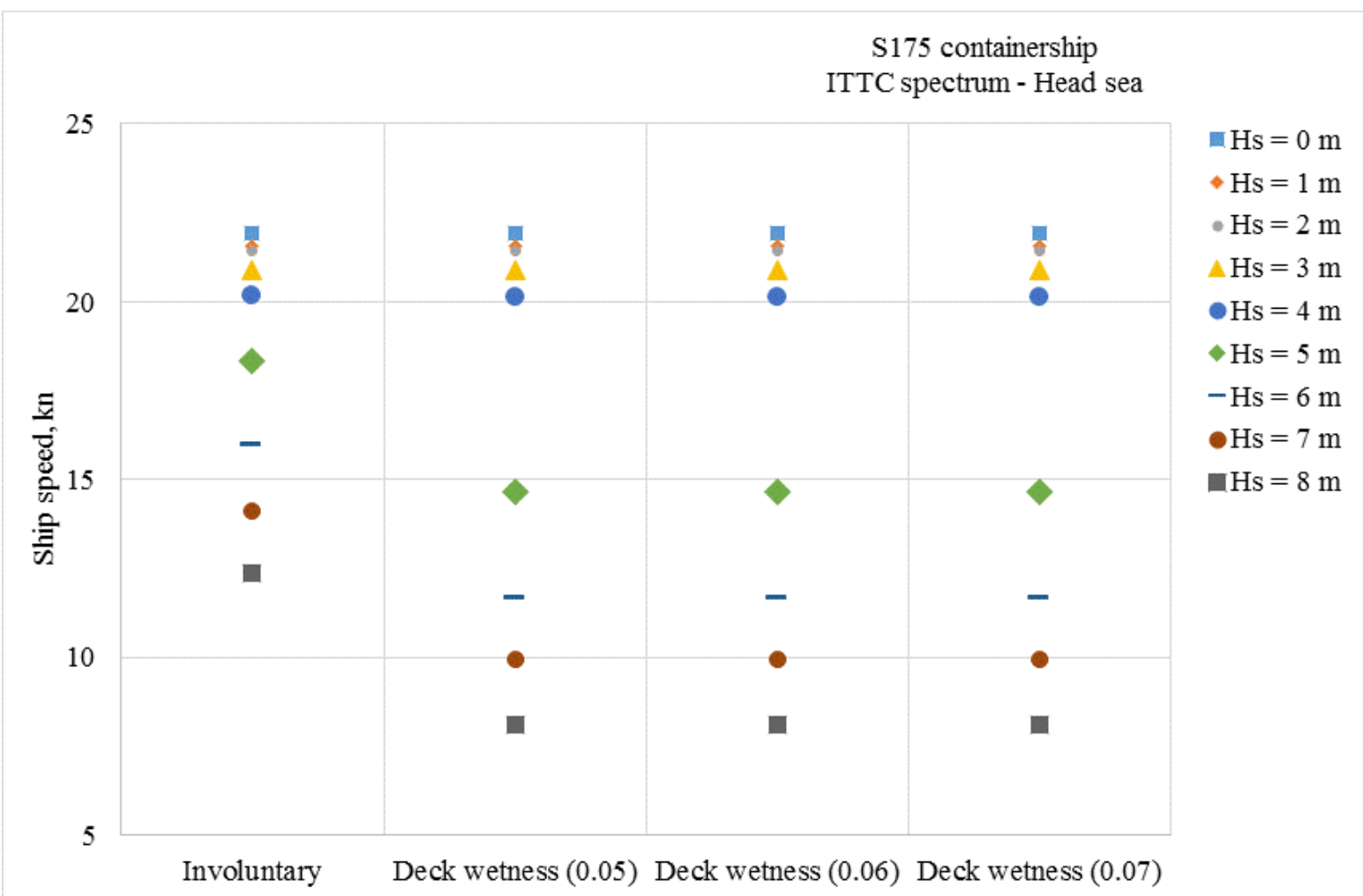

Figure 7. The effect of deck wetness limiting value on attainable ship speed (head sea)

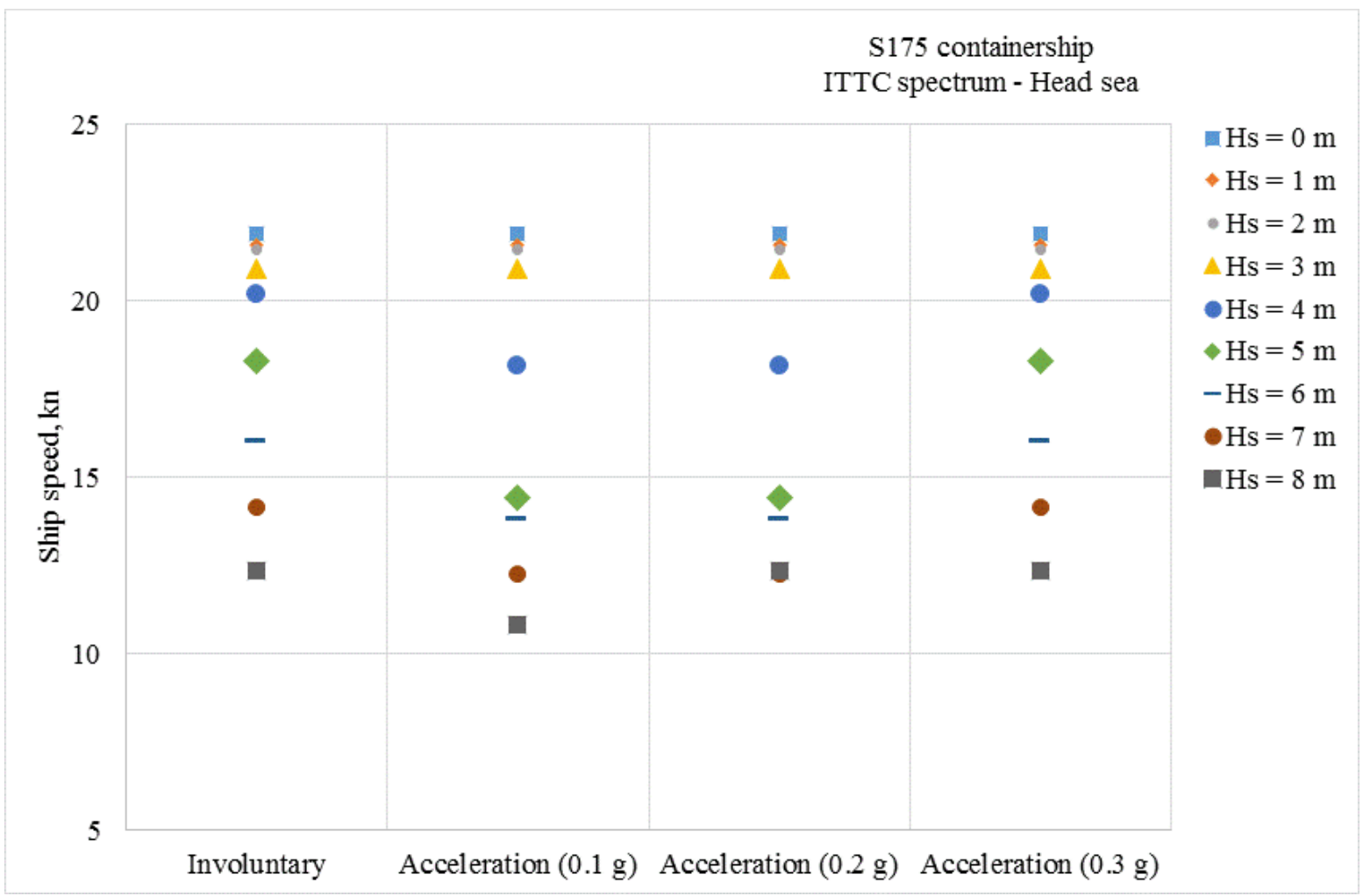

Figure 8. The effect of acceleration limiting value on attainable ship speed (head sea) 


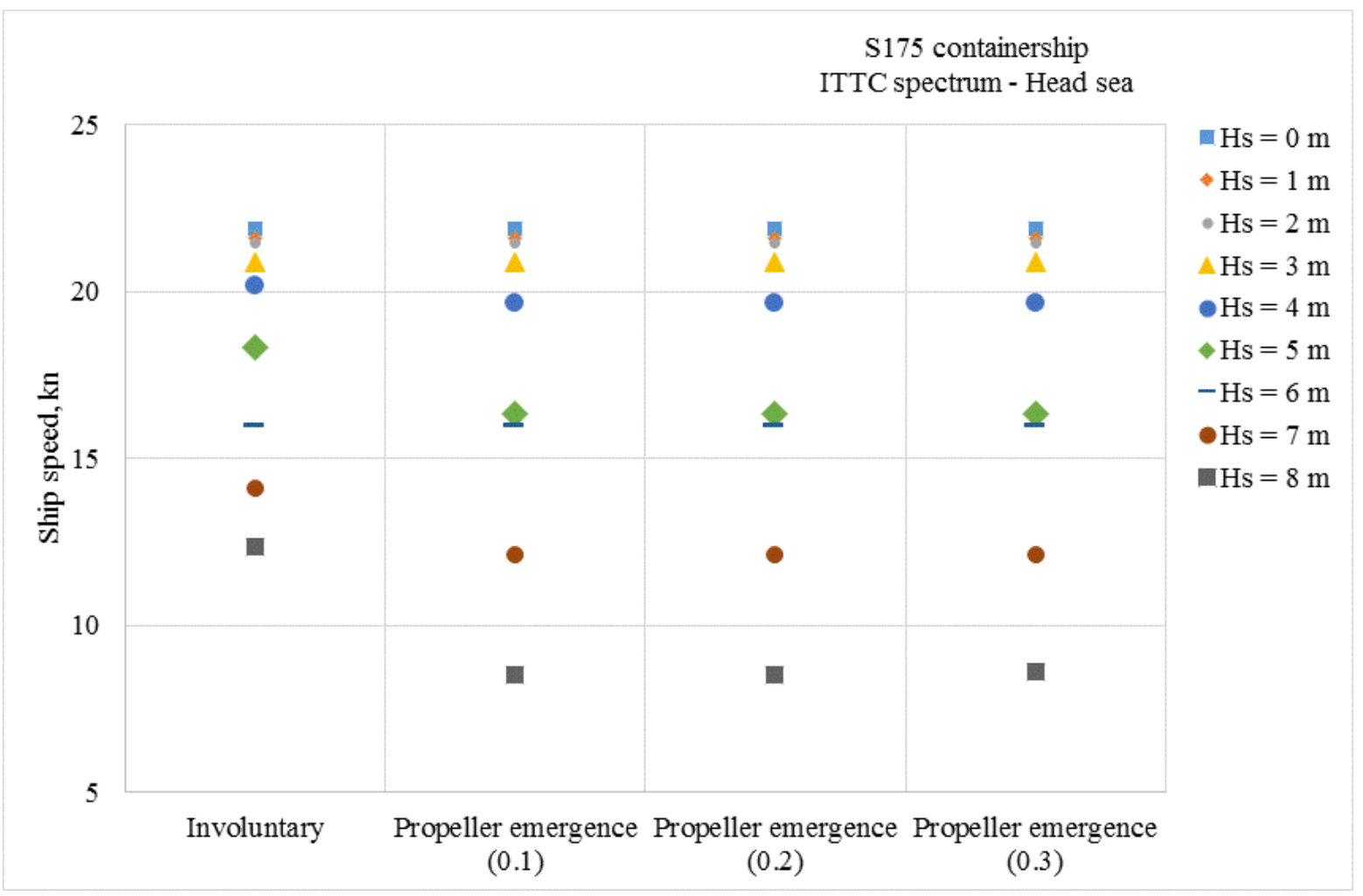

Figure 9. The effect of propeller emergence limiting value on attainable ship speed (head sea)

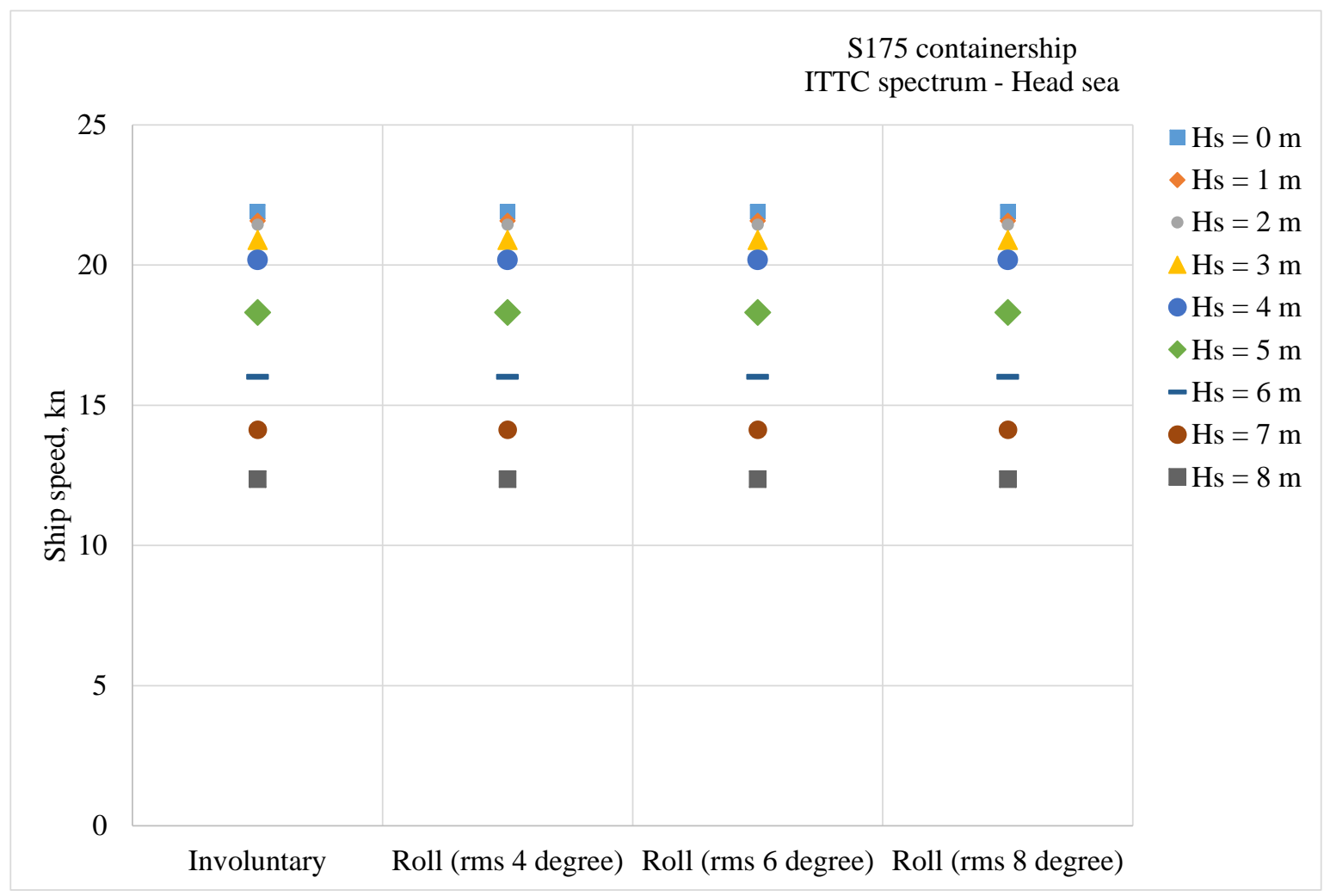

Figure 10. The effect of roll limiting value on attainable ship speed (head sea) 


\subsection{Following sea case}

The attainable speeds for the ship in following waves are shown in Fig. 11. The curves refer to involuntary speed reduction and to different cases of limiting values of voluntary speed reduction criteria. As for the head sea case, the master would reduce main engine power at the weather condition of approximately $3 \mathrm{~m}$ significant wave height. This would happen mainly due to propeller emergence. In the range of significant wave height values of 3 to 8 meters, the attainable speed is still most reduced when accounting for propeller racing (up to $11.3 \mathrm{kn})$.

Figs. 12 to 15 show very low sensitivity of final result (attainable ship speed) on criteria limit variations. When taking into account deck wetness and propeller emergence, the values of voluntarily reduced speed starts diverging from involuntarily reduced speed at $H_{\mathrm{s}}=6 \mathrm{~m}$ and $H_{\mathrm{s}}=3 \mathrm{~m}$, respectively. However, the effect of different limiting values on speed is negligible. As for head sea case, rolling criteria does not have any effect (Fig. 16).

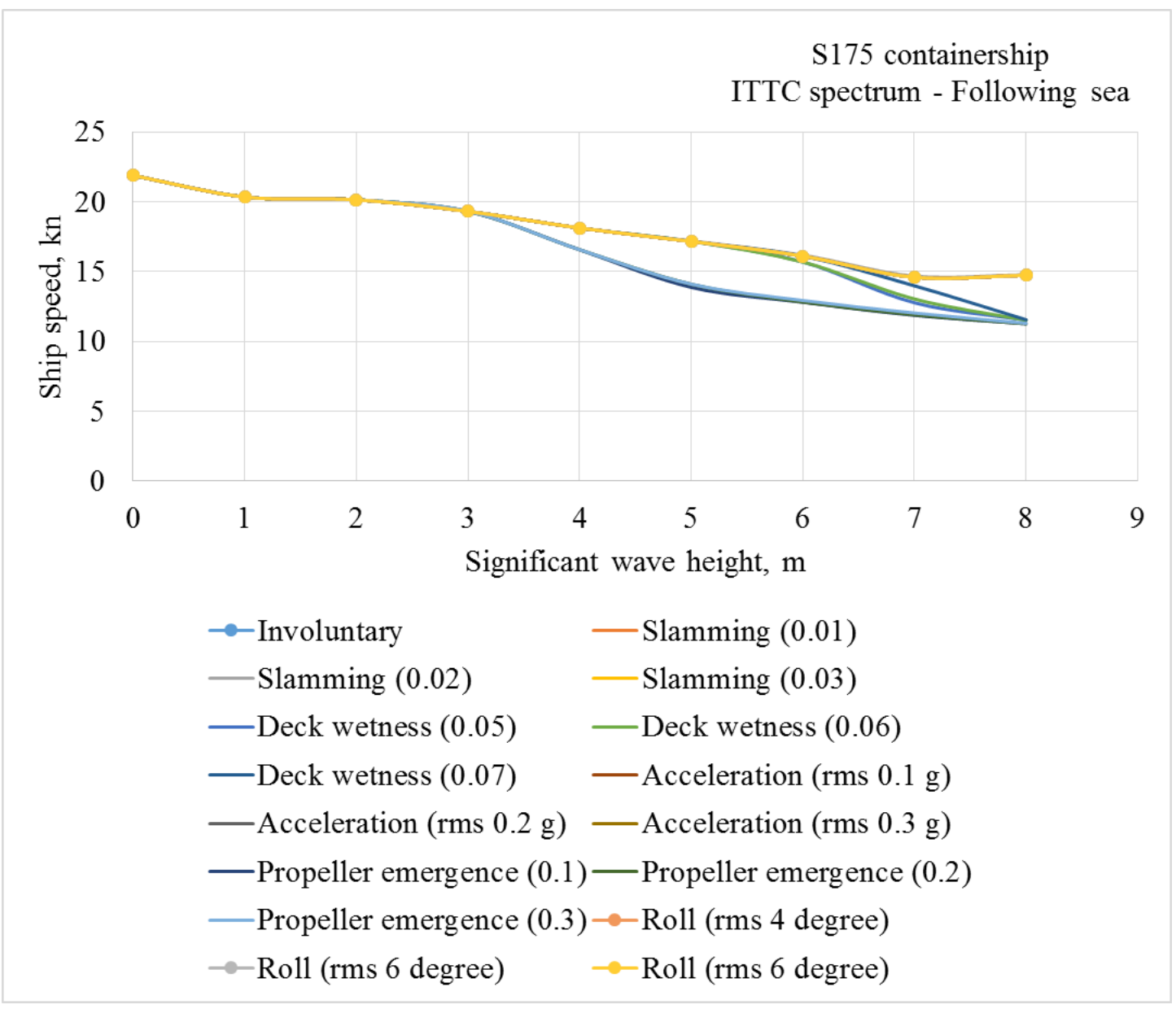

Figure 11. Ship speed loss for following sea 


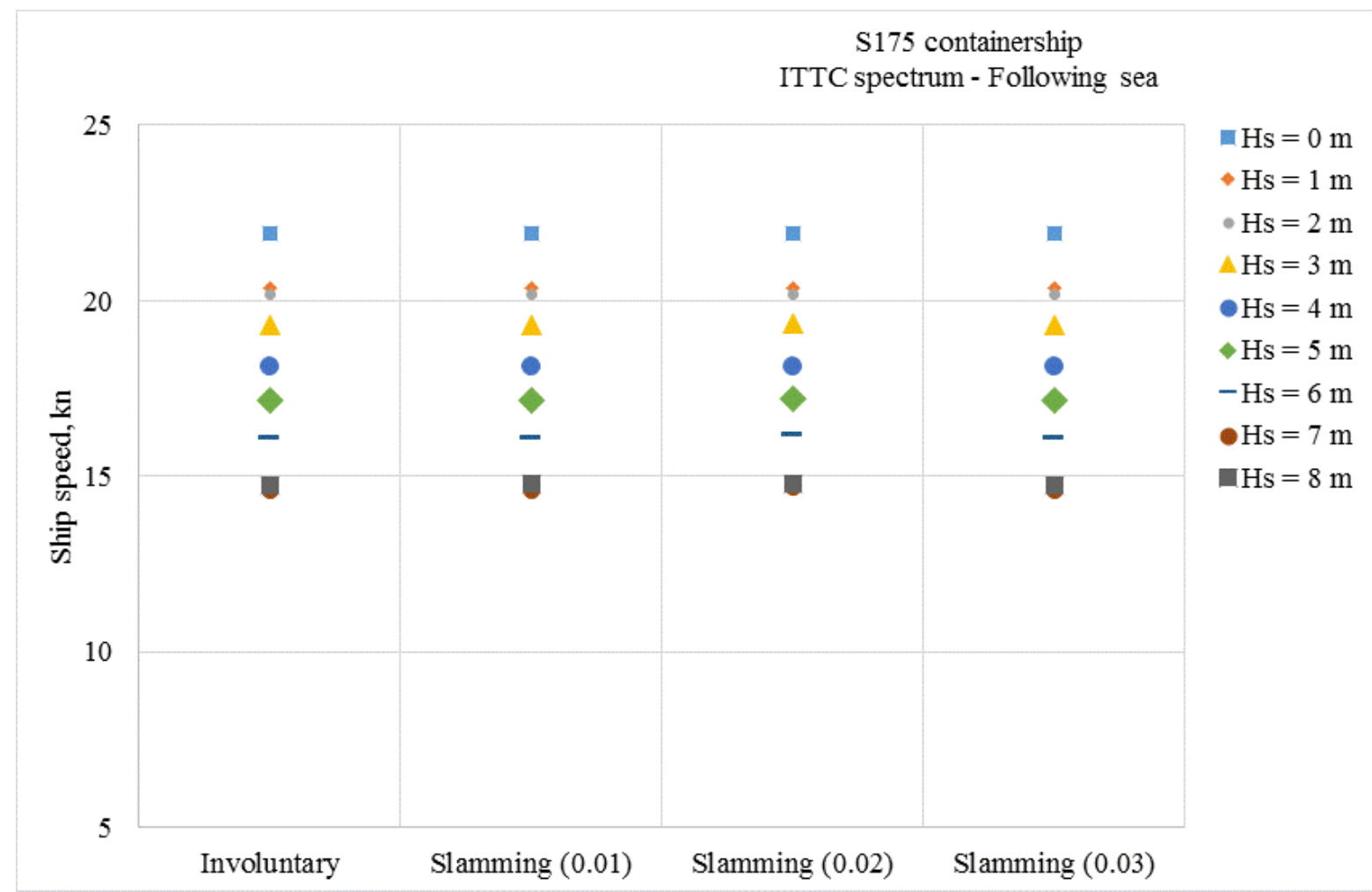

Figure 12. The effect of slamming limiting value on attainable ship speed (following sea)

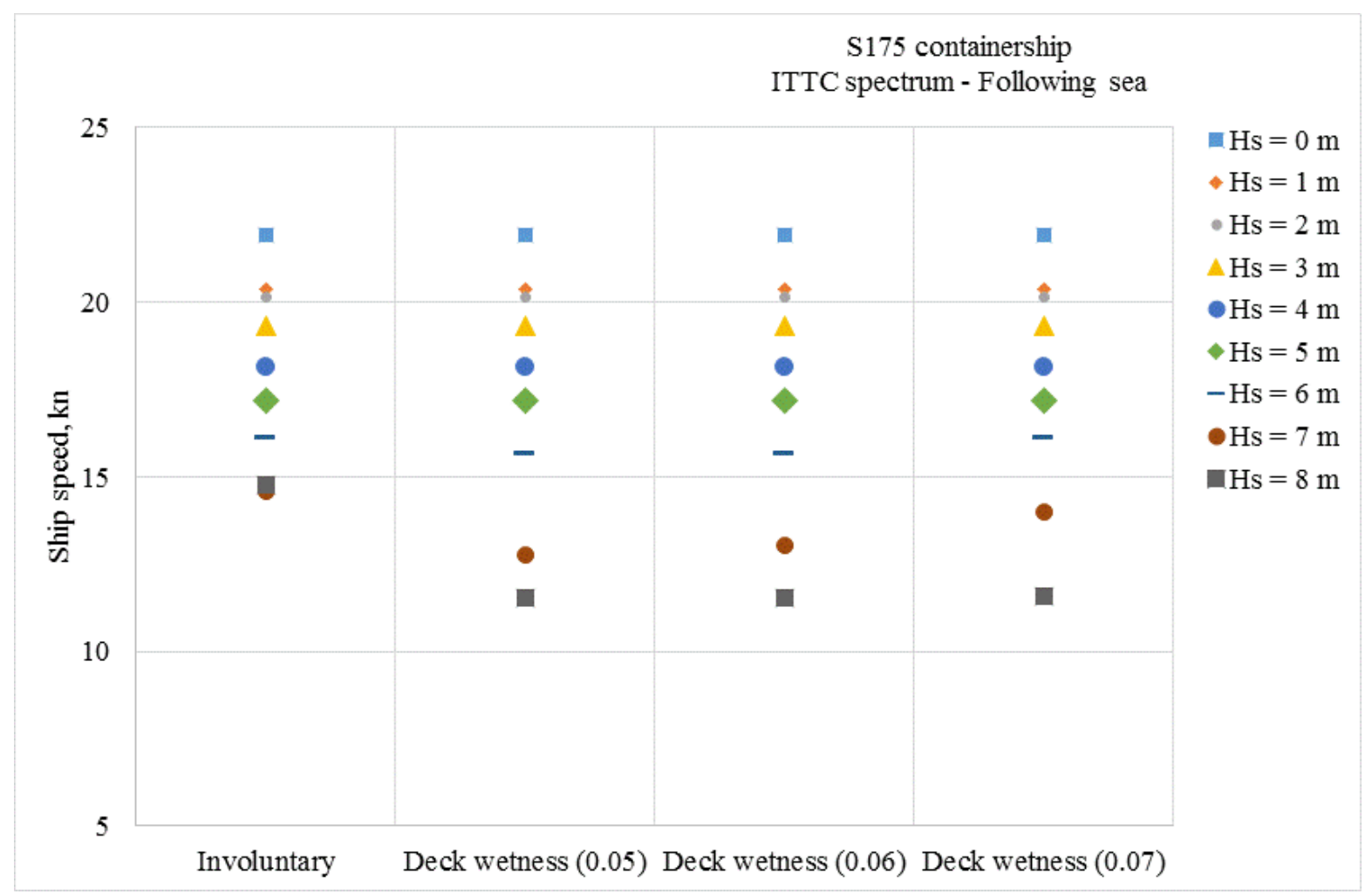

Figure 13. The effect of deck wetness limiting value on attainable ship speed (following sea) 


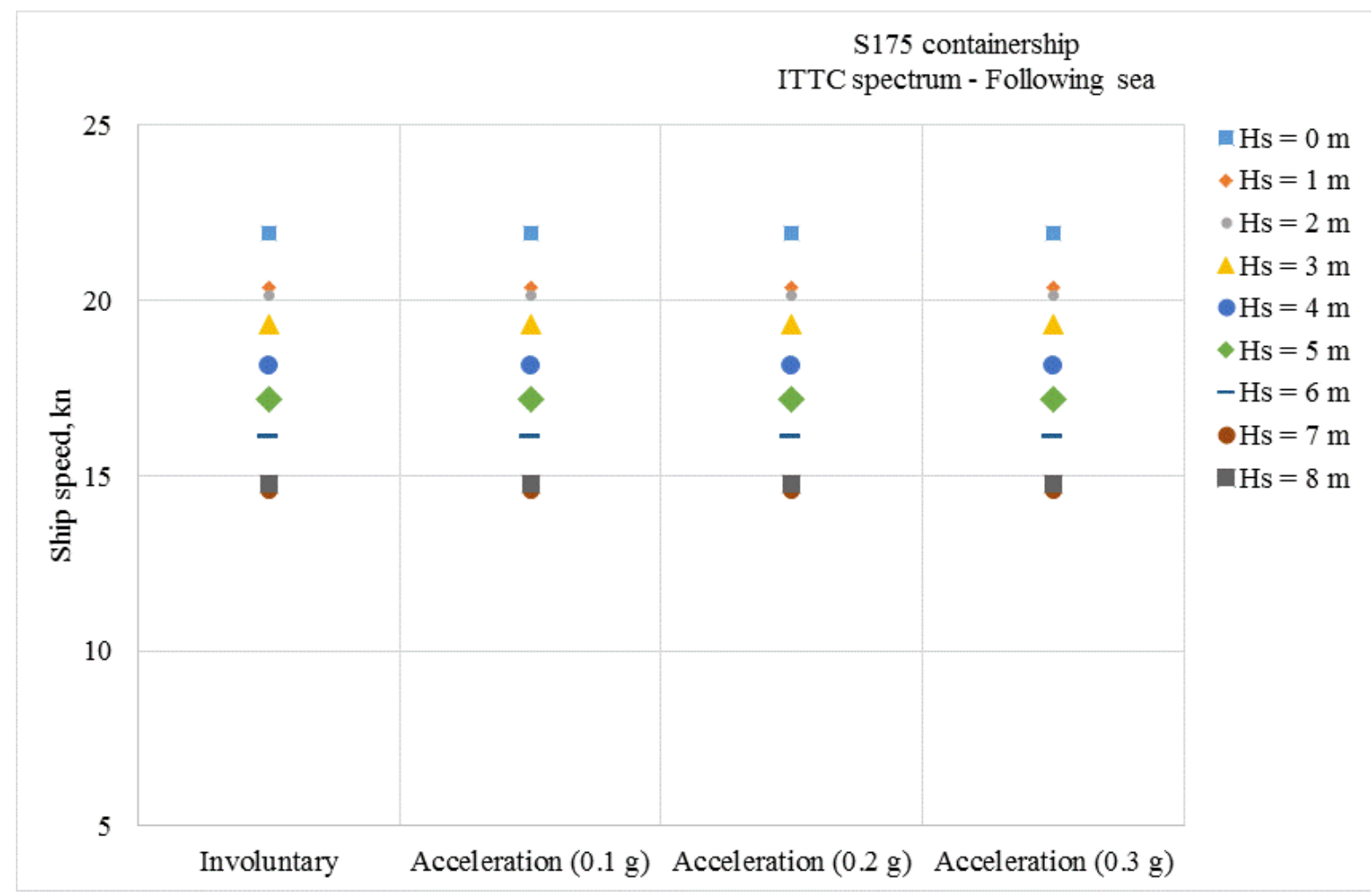

Figure 14. The effect of acceleration limiting value on attainable ship speed (following sea)

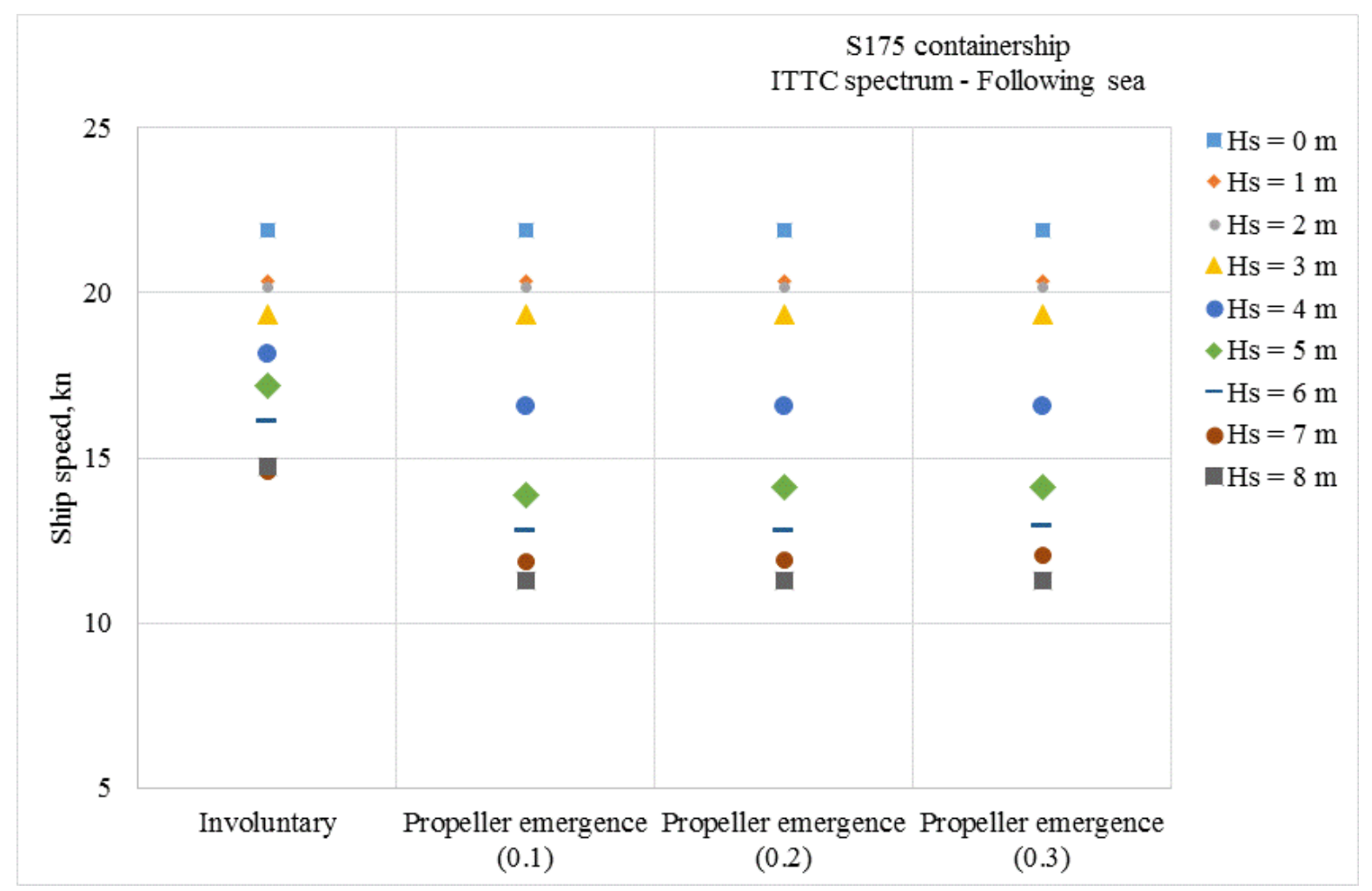

Figure 15. The effect of propeller emergence limiting value on attainable ship speed (following sea) 


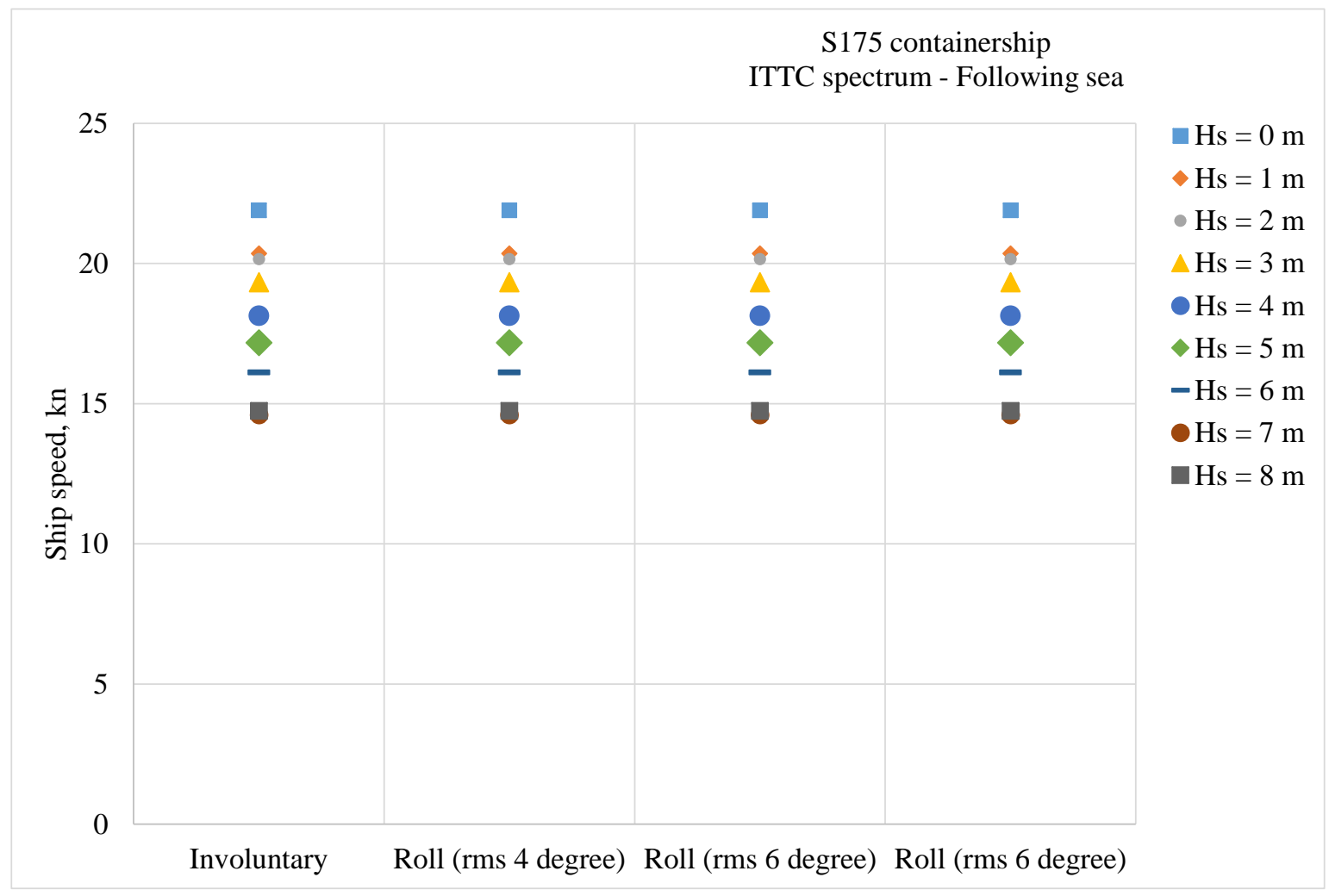

Figure 16. The effect of roll limiting value on attainable ship speed (following sea)

\subsection{Beam sea case}

The attainable speeds for the ship in beam waves are shown in Fig. 17. The curves refer to involuntary speed reduction and to different cases of limiting values of voluntary speed reduction criteria. The master would reduce main engine power at the weather condition of approximately $2 \mathrm{~m}$ significant wave height. This would happen due to excessive rolling. At higher waves (significant wave height values of 7 meters and more), the attainable speed will be reduced due to excessive accelerations.

Figs. 18 to 20 show that, as expected, slamming, deck wetness and propeller emergence will not occur in beam seas. However, when taking into account the most stringent acceleration and roll limit (Fig. 21 and 22), the values of voluntary reduced speed starts diverging from involuntary reduced speed at $H_{\mathrm{s}}=7 \mathrm{~m}$ and $H_{\mathrm{s}}=2 \mathrm{~m}$, respectively. In reality, in case of excessive rolling, the master would probably change the course as well in order to decrease unpleasant motion. 


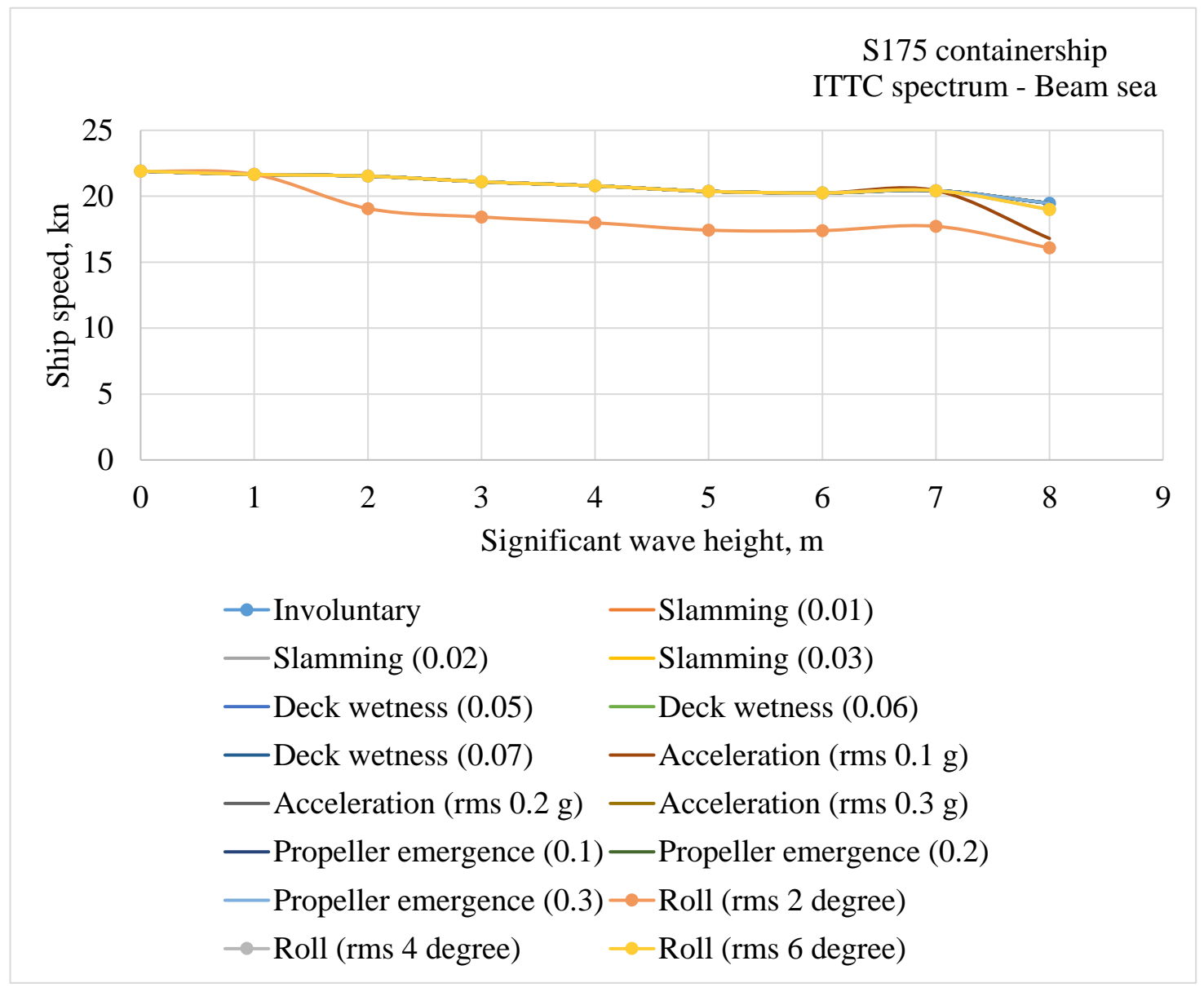

Figure 17. Ship speed loss for beam sea 


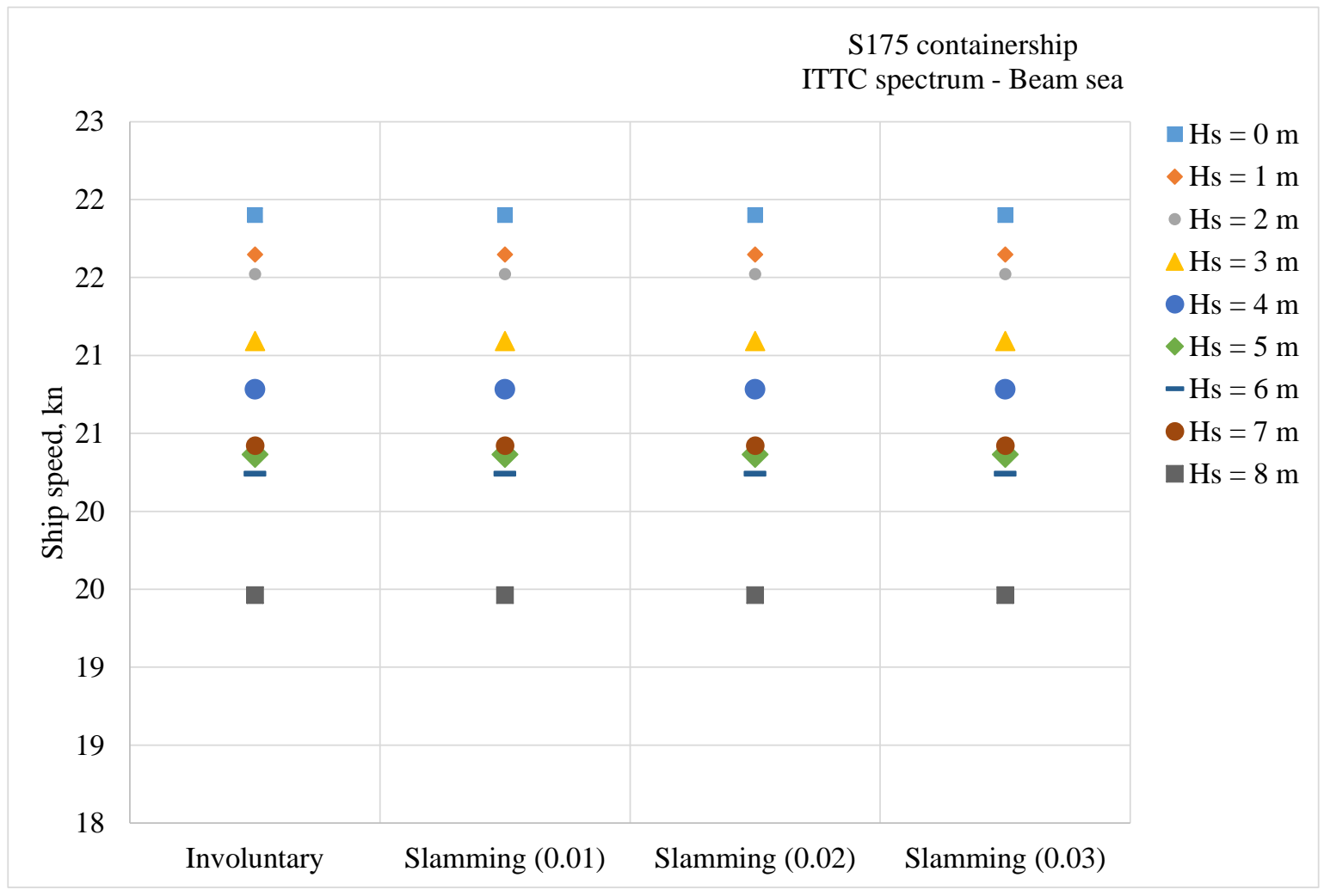

Figure 18. The effect of slamming limiting value on attainable ship speed (beam sea)

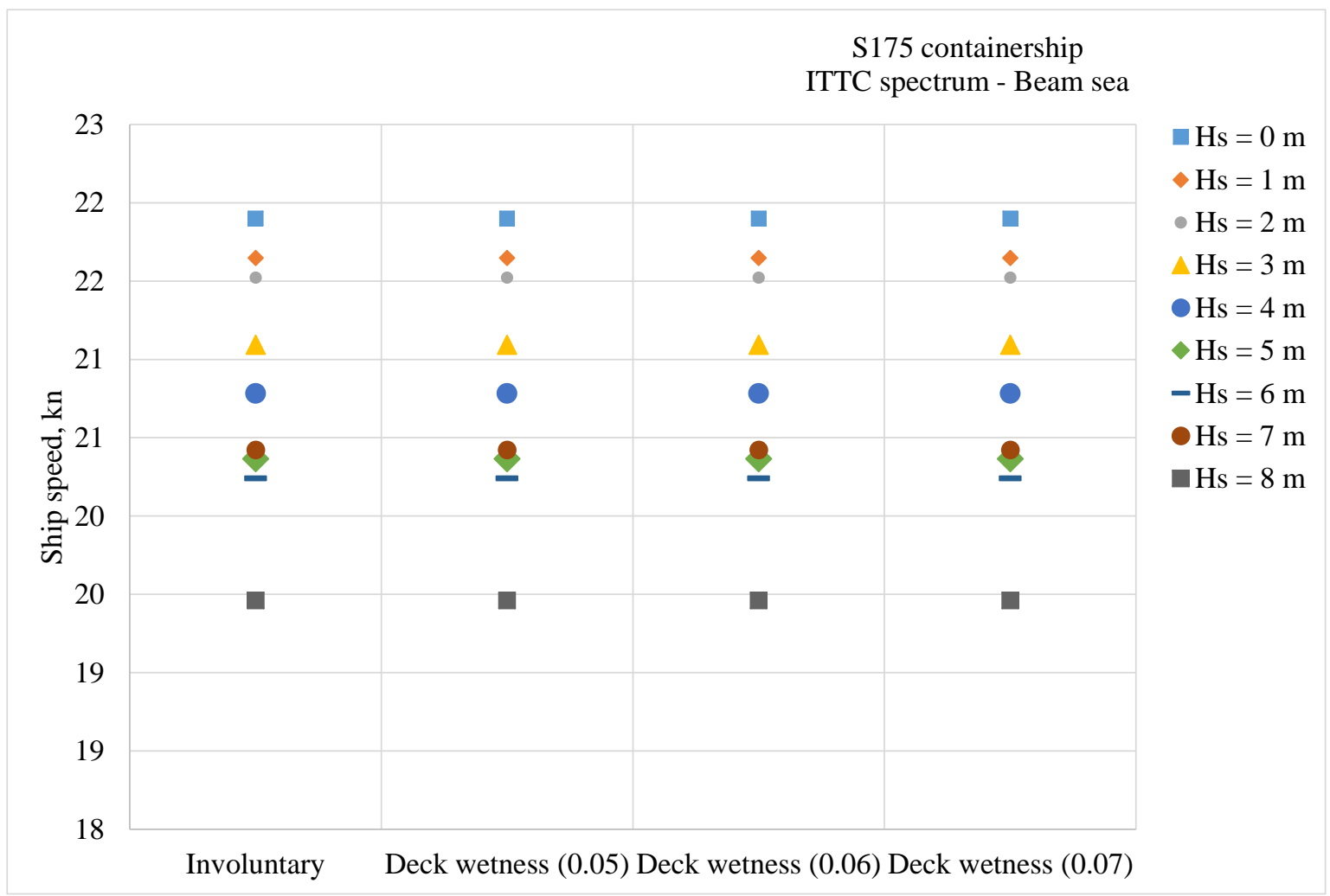

Figure 19. The effect of deck wetness limiting value on attainable ship speed (beam sea) 


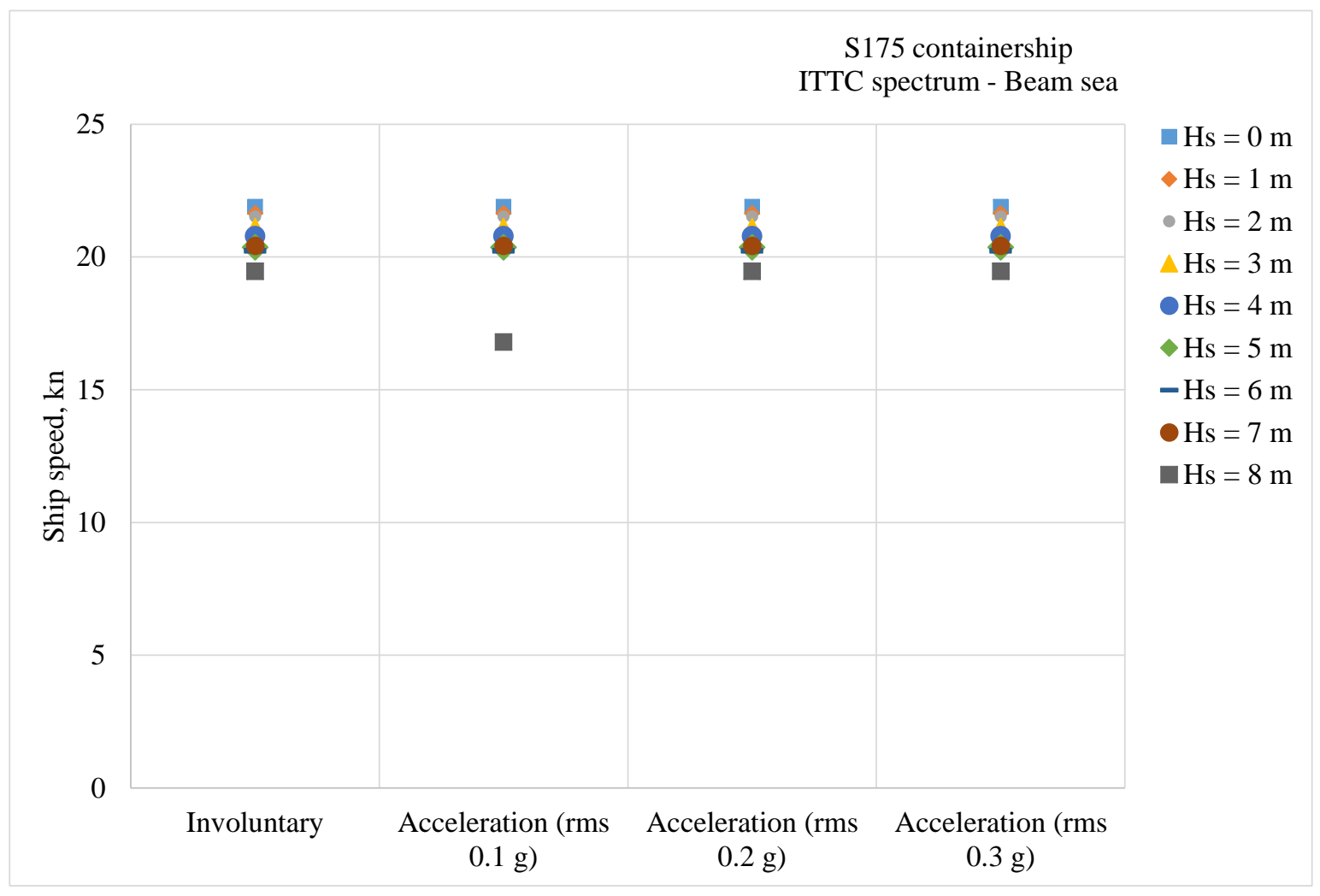

Figure 20. The effect of acceleration limiting value on attainable ship speed (beam sea)

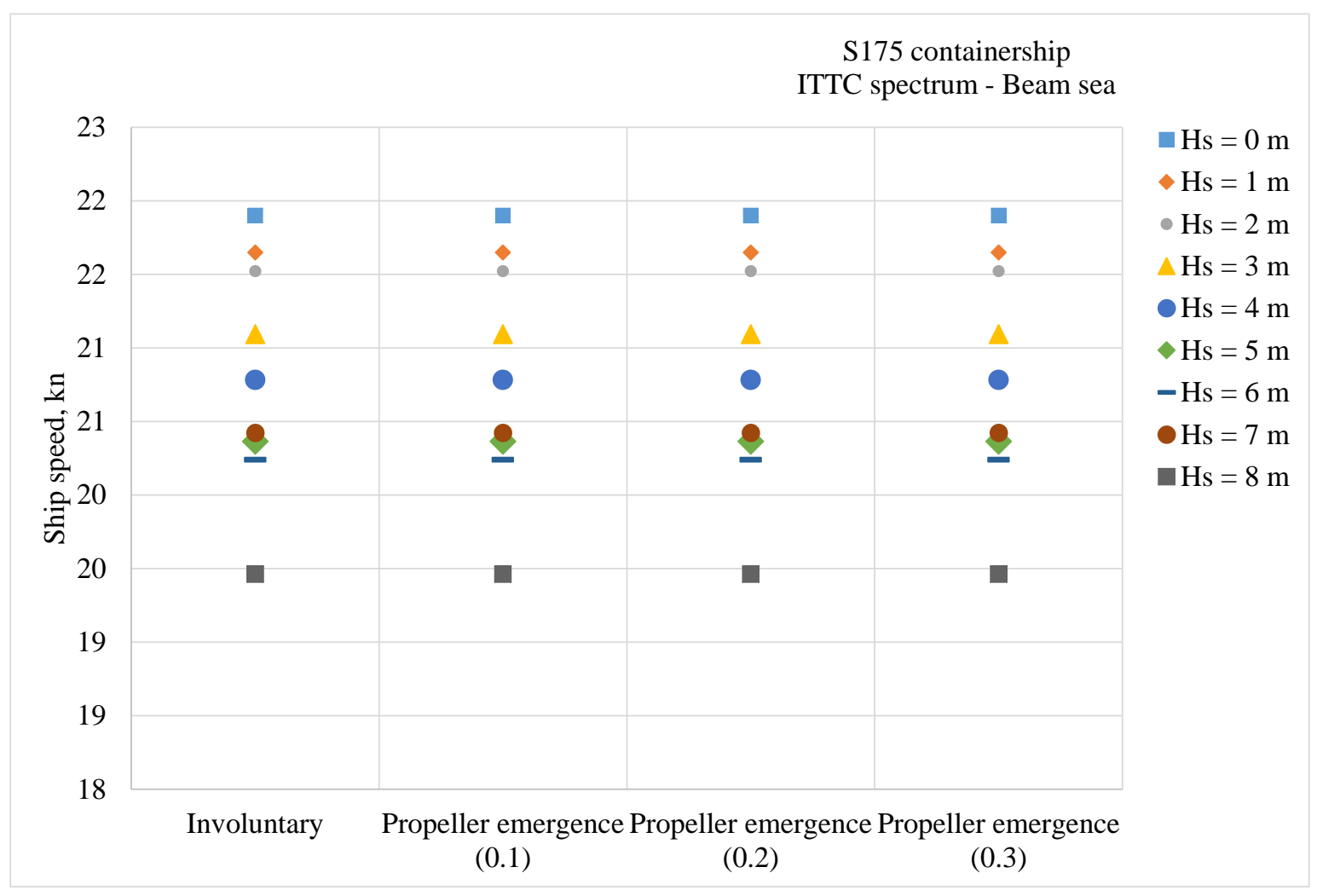

Figure 21. The effect of propeller emergence limiting value on attainable ship speed (beam sea) 


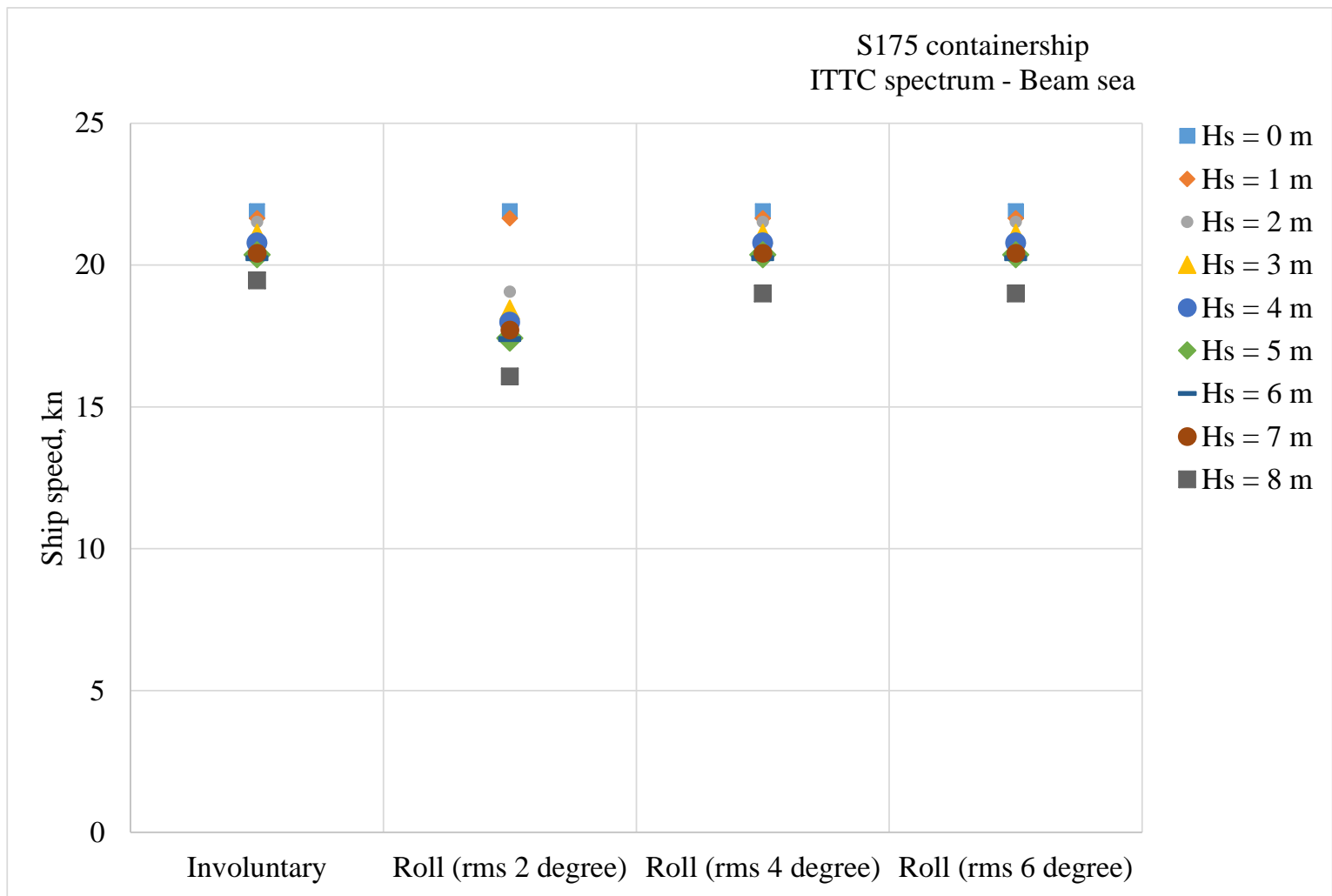

Figure 22. The effect of roll limiting value on attainable ship speed (beam sea)

\section{Conclusion}

One of the important segments of the ship speed drop in real weather conditions is voluntary ship speed reduction. This situation occurs in higher sea states when the captain judges that maintaining the current speed may compromise the ship, cargo or people on board, and decides to reduce deliberately the speed of the ship. The reasons and criteria due to which the captain decides to reduce speed are extremely subjective and dependent on the experience and the personality of the captain. This paper analyses the impact of variations of the limiting values of certain criteria due to which the captain intentionally reduces the ship speed. The influence of the limit values of slamming, deck wetness, excessive acceleration, propeller emergence and roll criteria at different significant wave heights of head, following and beam sea are analysed.

For both head and following sea cases, the master would reduce main engine power at the weather condition of approximately $3 \mathrm{~m}$ significant wave height and the wave length that is approximately half ship length. At head waves, the variations of limit acceleration values have evident impact on estimated ship speed. Due to stricter limiting rms value of $0.1 \mathrm{~g}$, estimated speed varies up to 4 knots. This is not the case for the effect of propeller emergence limiting value on attainable ship speed. The effect of considering this criterion is visible, but attainable ship speed value is not sensitive to the variation of the limiting values.

At following sea, voluntary speed reduction would happen mainly due to propeller emergence. In the range of significant wave height values of 3 to 8 meters (which corresponds to wave length - ship length ratio approximately 0.5 to 1.0 ), the attainable speed is, due to propeller racing, reduced up to $11.3 \mathrm{kn}$.

The master would voluntary reduce ship speed at the weather condition of approximately $2 \mathrm{~m}$ significant wave height at beam sea. This would happen due to excessive 
rolling. At waves of significant wave height values of 7 meters and more, the speed will be reduced due to excessive accelerations.

The analysis shows quite low sensitivity of final result (attainable ship speed) on criteria limit variations. When taking into account deck wetness, propeller emergence and roll the values of involuntary reduced speed starts diverging from voluntary reduced speed at $H_{\mathrm{s}}=6$ $\mathrm{m}, H_{\mathrm{s}}=3 \mathrm{~m}$, and $H_{\mathrm{s}}=2 \mathrm{~m}$ respectively. However, the effect of different limiting values on speed is almost negligible. The main reason is that the small change in probability (for example for slamming and deck wetness but also for propeller emergence) slightly affect the threshold values that lead to each phenomena. The excessive accelerations and roll criteria limits are expressed as rms values and the difference of threshold values in that case is more pronounced. The model will be further improved by modelling of "virtual captain" whose reactions will be modeled within the specified range of probability. The additional criteria related to specific ship type, such as maximum forces acting on the containers for container ships, will be included.

\section{ACKNOWLEDGEMENTS}

This work was supported by the Research Council of Norway through the Centres of Excellence funding scheme AMOS, project number 223254, University of Rijeka (contract no. 13.09.1.1.05) and Croatian science foundation (project 8722 and project 8658).

\section{REFERENCES}

[1] Guedes Soares, C. 1990. Effect of Heavy Weather Maneuvering on the Wave Induced Vertical Bending Moments in Ship Structures. Journal of Ship Research. 34(1), pp. 60-68.

[2] Prpić-Oršić, J., Parunov, J., Šikić, I. 2014a. Operation of ULCS - real life. International Journal of Naval Architecture and Ocean Engineering, Vol. 6, No 6, pp. 1014-1023. http://dx.doi.org/10.2478/ijnaoe-2013$\underline{0228}$

[3] Faltinsen, O.M. 2005. Hydrodynamics of High-Speed Marine Vehicles, Cambridge University Press

[4] Dubrovskiy, V.A., 2000. Complex comparison of seakeeping: method and example. Marine Technology, 37(4), pp. 223-229.

[5] Prpić-Oršić, J., Faltinsen, O. M., Parunov, J. 2015. The effect of voluntary speed reduction criteria on attainable ship speed, $16^{\text {th }}$ Congress IMAM 2015, Pula, pp. 143-149

[6] Kwon,Y.J. 2008. Speed Loss Due to Added Resistance in Wind and Waves. The Naval Architect, RINA (U.K.), pp. 14-16.

[7] Minoura, M. \& Naito, S. 2008. Statistical Estimation of Ship Speed Loss by Monitoring Data. Proceedings of the 6th Osaka Colloquium on Seakeeping and Stability of Ships, Osaka, Japan, pp. 37-42.

[8] Dallinga, R., Flikkema, M., Grin, R. 2008. Challenging wind and waves - their impact on fuel consumption. MARIN report 94, pp. 1-3.

[9] Prpić-Oršić, J. \& Faltinsen, O.M. 2012. Estimation of Ship Speed Loss and Associated $\mathrm{CO}_{2}$ Emissions in a Seaway. Ocean Engineering, Vol. 44, No 1, pp. 1-10. http://dx.doi.org/10.1016/j.oceaneng.2012.01.028

[10] Faltinsen, O.M. Minsaas, K.J. Liapis, N. Skjordal, S.O. 1980. Prediction of Resistance and Propulsion of a Ship in a Seaway. Proc. 13th Symposium on Naval Hydrodynamics, pp. 505-529.

[11] Blendermann, W. 1993. Schiffsform und Windlast-Korrelations-und Regressionanalyse von Windkanalmessungen am Modell, Report No. 533, Institut fur Schiffbau der Universitat Hamburg

[12] Blendermann, W. 1994. Parameter identification of wind loads on ships, J. Wind Engng. Ind. Aerodyn

[13] Blendermann, W. 1995. Estimation of wind loads on ships in wind with a strong gradient. Proceedings of the 14th OMAE, ASME, New York

[14] Harris, R.I. 1971. The Nature of the Wind,the Modern Design of Wind Sensitive Structures, Const. Ind. Res. \& Inf. Assn., London 
[15] Smogeli, O.N. 2006. Control of Marine Propellers - From Normal to Extreme Conditions. PhD-thesis 2006:187, Faculty of Engineering Science \& Technology, Trondheim

[16] Medica, V. \& Mrakovčić, T. 2002 Compressor map representation in numerical simulations of turbocharged diesel engine steady and transient operation. Proceedings of the Symposium Motors and Vehicles, Zagreb, pp. $1-10$

[17] Faltinsen, O.M. \& Svensen, T. 1990. Incorporation of Seakeeping Theories in CAD. CFD and CAD in Ship Design, Elsevier Science Publishers B. V.

[18]Journee, J.M.J. \& Meijers, J.H.C. 1980. Ship Routeing for Optimal Performance. Transactions IME, Rapport 0529_P, Delft

[19] ITTC 1978. Report of the Seakeeping Committee. In: Proceedings of the 15th International Towing Tank Conference, Vol. 1. The Hague, Netherlands

[20] Ochi, M. K. 1964. Prediction of Occurrence and Severity of Ship Slamming at Sea, 5th Symposium on Naval Hydrodynamics, Bergen, Norway, pp. 545-549.

[21] Prpić-Oršić, J., Vettor, R., Faltinsen, O.M., Guedes Soares, C. 2014b. Influence of ship routes on fuel consumption and $\mathrm{CO}_{2}$ emission. The $2^{\text {nd }}$ Congress Maritime Technology and Engineering - MARTECH 2014., Lisabon, Portugal, pp. 857-864

Submitted: 11.03.2016. Jasna Prpić-Oršić, jasnapo@ @ riteh.hr

Faculty of Engineering, University of Rijeka, Vukovarska 58, 51000 Rijeka,

Accepted: 5.05.2016. Croatia and Centre for Autonomous Marine Operations and Systems (AMOS), Trondheim, Norway

Odd Magnus Faltinsen

Centre for Autonomous Marine Operations and Systems (AMOS),

Department of Marine Technology, NTNU, Trondheim, Norway

Joško Parunov

Faculty of Mechanical engineering and Naval Architecture, University of Zagreb, Croatia 